\title{
Produção do conhecimento, interdisciplinaridade e estruturalismo
}

\author{
DOI: $10.3395 /$ reciis.v3i3.271 pt
}

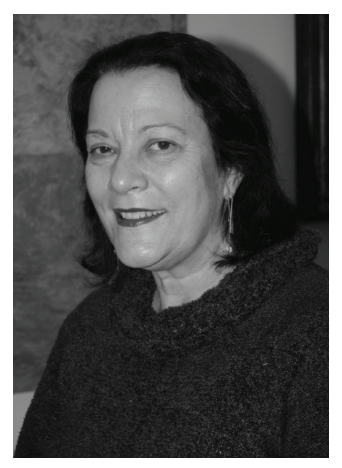

\section{Maria de Fátima Gonçalves Moreira Tálamo} Escola de Comunicações e Artes, Universidade de São Paulo, São Paulo, Brasil maria.talamo@pq.cnpq.br

\begin{abstract}
Resumo
Apresentação da organização da ciência moderna, identificando ocorrências da produção de saberes segundo contextos formais e informais, e de sua transição paradigmática para a pós-modernidade, com o recurso à interdisciplinaridade, cujo funcionamento seguindo princípio de economia dos sistemas simbólicos, permite a dialogia e a consolidação das humanidades. Exemplifica-se, tal fenômeno, com o estruturalismo, que na contemporaneidade continua exercendo papel importante na organização de novos campos de investigação, como o das ciências do impreciso e o da ciência da informação.
\end{abstract}

\section{Palavras-chave}

ciência moderna; ciência pós-moderna; estruturalismo; interdisciplinaridade; conhecimento

\section{Introdução}

O início do século 21 encontra-se marcado por grandes alterações, visíveis em todos os níveis, econômico, político, social e cultural, mas difíceis de serem reunidas em uma só denominação. Assim, sociedade da informação, sociedade do conhecimento, sociedade da aprendizagem, sociedade pós-moderna e sociedade globalizada são alguns nomes que tendem a simplificar as grandes mudanças que incidem sobre o lugar a partir do qual falamos e produzimos as representações do mundo, os saberes e o conhecimento científico. Caraça (2004, p.185) associa semelhante dificuldade denominativo/ conceitual à percepção evidente que hoje temos de que somos um sistema complexo, isto é, "um sistema cujo desempenho depende da evolução do contexto que lhe serve de suporte - e não sabemos onde termina o nosso sistema e começa o contexto e vice-versa". O impacto dessa situação na produção do conhecimento, especialmente nos inúmeros saberes que se constituíram ao longo dos últimos quatro séculos, põe em pauta a discussão sobre as referências que lhes serviram de base e a necessidade de redefinição das disciplinas, especialmente no que tange às noções de objeto, limites disciplinares e métodos. A partir desses pressupostos, realiza-se a caracterização sumária das formas de produção dos saberes desde o renascimento, assinalando o caráter limitante e rigoroso da ciência moderna, cujos procedimentos operacionais homogeneizantes instituem uma única modalidade válida de saber: o conhecimento científico. Seu avanço significativo esteve associado à observação sistemática e à tradução quantitativa dos dados coletados. Pontuam-se, 
na seqüência, os elementos característicos da pós-modenidade, inserindo a interdisciplinaridade como um dos adjuvantes importantes desse processo. Exemplifica-se a interdisciplinaridade através do estruturalismo lingüístico e do seu impacto no campo das humanidades. Finaliza-se o texto, com dois exemplos que demonstram a importância dos mecanismos conceituais para a funcionalidade da interdisciplinaridade: o de análise estrutural para aas ciências do impreciso e o de estrutura para a ciência da informação.

\section{Formas de produção dos saberes e o triunfo da ciência moderna}

As práticas científicas responsáveis pela geração do conhecimento estabelecido experimentaram variações e articulações importantes no decorrer do tempo, no que tange especialmente aos seus contextos formais e informais de produção e circulação. Segundo a relação que assumem tais contextos - desde a complementaridade até a hierarquização - tem-se formações específicas de produção, organização e circulação do conhecimento que caracterizam o modo pelo qual os diferentes saberes se integram à sociedade.

Com o renascimento, por exemplo, o movimento humanista inova ao se opor ao saber convencional dos escolásticos que reinava na idade média. Aliás, estima-se, como observa Burke (2003 p.40-41), que os humanistas cunharam as palavras "escolásticos" e "idade média" justamente para a obtenção de uma definição mais clara e direta de sua própria posição de crítica ao espaço institucionalizado do conhecimento, com a conseqüente criação de um espaço alternativo de debate, a "academia". De fato, à época, parte significativa dos debates de idéias se desenvolviam fora do ambiente da universidade, seja nas academias ou mesmo em ambientes informais: o matemático Paolo Toscanelli, por exemplo, obtinha informações sobre as rotas para as Índias interrogando viajantes que passavam por Florença. Nas academias, onde o ambiente era menos formal do que um departamento universitário, os humanistas debatiam e produziam idéias inovadoras. Isso sinaliza para uma dinâmica diversificada de produção de saberes comprometida igualmente com diferentes contextos e modos de comunicação : da dialogia e das fontes informais de informação até os espaços e fontes institucionalizados (BURKE, 2003, p.41).

Com a revolução científica o foco da reflexão investigativa desloca-se do humanismo fundado na tradição clássica para a natureza impregnada pela idéia de mecanicismo, inicia-se então a estrutura da ciência moderna. Permanece, no entanto, ainda que de forma tímida, o movimento de incorporação dos saberes alternativos ao conhecimento estabelecido.

Consolidam-se de forma contínua e crescente, a partir do século 18, iniciativas de organização diversificada de lugares de formação, embora não se verificasse alteração significativa dos seus atores. Ao lado das diferentes universidades já constituídas, aparecem instituições, algumas vinculadas às próprias universidades, como os jardins botânicos e laboratórios, outras independentes, como as sociedades científicas e as academias, que consolidam práticas de circulação das inovações advindas do pensamento iluminista.

É importante observar que as diferentes formas de instituições e organizações impactaram diretamente não só os processos de produção do conhecimento mas também suas formas de comunicação. Enquanto nas sociedades científicas redes de estudiosos eram formadas, as academias acabaram por ampliar o público no compartilhamento das novas idéias, tidas como inovações, sob a forma de palestras sobre temas diversificados, enunciadas na língua nacional. A substituição parcial do latim, língua usual das universidades, pela língua nacional como veículo de comunicação, integra esses "novos lugares e bases da cultura", conforme nomeados por Burke (2003, p.47), à dinâmica de uma comunicação social que seria solidificada séculos depois, com a integração de outras práticas culturais à circulação do conhecimento.

No entanto, tais alterações tiveram uma função secundária face ao vigoroso desenvolvimento do pensamento iluminista de natureza unificadora e universal. As concepções mecanicistas que o caracterizam impôs a importação do modelo de estudos da física para a compreensão de fatos humanos e culturais. A grande metáfora assim estabelecida se propôs como recurso expressivo que desempenhou papel importante nos processos cognitivos, condicionando o modo pelo qual se observava e se compreendia o mundo. A percepção conduz, nesse sentido, à produção das representações. Não é por acaso, portanto, que o conhecimento da ciência clássica seja tão dependente dos dados. Esses acabam por simbolizar a decomposição, a simplificação do complexo, a divisão do todo em suas partes e, em muitos casos, conduz à afirmação da dependência do qualitativo ao quantitativo. Esse é reconhecidamente o ponto de partida para a organização moderna do conhecimento humano em disciplinas.

A concepção mecânica do mundo, fundada nas dualidades corpo/alma, parte/todo, simples/complexo, também separa o homem da natureza e atribui ao método a função excepcional da criação do conhecimento. Com a criação das organizações de fomento à pesquisa no século 18 , o conjunto de vocábulos associados à pesquisa passa a ter um uso mais freqüente. Esses vocábulos participam não só de uma origem comum, cujo núcleo é "busca", mas evidenciam também o caráter sistemático e profissional da atividade investigativa, cujo resultado ou produto apresenta-se como conhecimento útil. Assim, o significado do termo "pesquisa" passa a agregar traços que o diferenciam da curiosidade e da especulação. Se é fato que o homem liberto das amarras institucionais produz idéias brilhantes, não é menos verdade que pôlas em prática exige contextos institucionais. Assim, a efervescência das idéias desse período, que conduziu à disciplinarização, é contida à medida que a matriz que a expressa formaliza-se na instituição universitária. Dito de outro modo, embora as inovações do século 18 tenham sido importantes para a consolidação das práticas disciplinares, há de se convir que "é virtualmente inevitável que as instituições que as integraram mais cedo ou mais 
tarde se cristalizem e se tornem obstáculos para inovações adicionais" (BURKE, 2003, p.53 ).

Credita-se, por sua vez, o avanço do conhecimento no século 19 fundamentalmente à ciência coincidindo com a emergência do positivismo, cujos mecanismos propiciaram conquistas importantes embora, como ressalta Hobsbawm (1996, p. 351) ele não tenha sido mais do que uma "justificação filosófica do método das ciências experimentais”. Na seqüência, como era de se esperar, método positivista e método científico passam a ser intercambiáveis e a idéia de progresso, tão cara à corrente, impõe a exigência da estrutura metodológica básica para o avanço do conhecimento.

A importância do método na ciência moderna pode ser interpretado como a expressão da secularização da sociedade no mundo do conhecimento, conferindo á ela um certo caráter democrático. Segundo Wallerstein (2004, p. 125), os cientistas não deixavam de afirmar que qualquer um poderia produzir o conhecimento, “ desde que utilizasse os métodos adequados”. Com isso, cria-se uma situação confortável no que se associa às questões sobre o que é bom e verdadeiro: o conhecimento das coisas boas constituíam o debate da filosofia, já o das verdadeiras era uma questão científica, dependente do método.

A dificuldade do reconhecimento das diferentes formas de olhar o mesmo problema, limitação evidente das estruturas que assentam o conhecimento moderno, esteve também na base da própria dinâmica da organização do conhecimento científico nas universidades. Ao institucionalizar uma organização do conhecimento, a universidade formaliza seus conteúdos de forma rigorosa, propiciando de modo crescente a especialização na sua geração e transmissão. É em síntese nesse contexto que o conhecimento organiza-se seguindo as matrizes disciplinares como referência.

De fato, até pelo menos as duas primeiras décadas do século 20, o pensamento motivado pela previsibilidade e pelas relações causais encontra nas várias manifestações do determinismo o seu apogeu e no reducionismo o seu triunfo. A disciplinarização resultante da divisão do todo formula a lógica dos currículos escolares e a organização da própria universidade. No entanto, não se pode ignorar, enfatizando o que já foi dito, que a história do conhecimento é plena de deslocamentos. "É uma história da interação entre outsiders e establishments, entre amadores e profissionais, empresários e assalariados intelectuais (BURKE, 2003, p.53). Mas é preciso também considerar que a organização clássica da universidade cuidará de maneira crescente de minimizar os deslocamentos entre os espaços de geração dos saberes. Institui-se, então, um conflito entre produção e organização do conhecimento científico no interior da própria instituição que os integra, a universidade.

O que parece fundamental a ser observado é que a partir do iluminismo, equacionam-se duas formas ou estruturas para a perpetuação da geração e transmissão de idéias. Uma estrutura teórica que contempla a constituição de um objeto e, sobretudo, institui o método para a distinção entre verdadeiro e falso e uma estrutura institucional que supõe a mediação de disciplinas para a realização efetiva do ensino. É essa a consistência desejada pelo próprio projeto da modernidade, ao propor como um dos seus pilares a ciência e o ensino (TÁLAMO \& SMIT, 2007). A partir daí cria-se efetivamente um problema, qual seja, o de resolver a contradição entre a ação necessariamente divergente da investigação com o mecanismo disciplinar que supõe discursos normalizadores. O conhecimento útil da ciência moderna tem na sociedade o seu beneficiário, mas depende diretamente dos efeitos multiplicadores do ensino para atribuir valores positivos ao seu modelo hegemônico. Assim o mecanismo disciplinar passa a ser o provedor necessário dos processos investigativos, limitando ou neutralizando, de certo modo, a expansão e o desenvolvimento de espaços alternativos para a produção do conhecimento. De fato, com o reforço da fragmentação disciplinar exigido pela estrutura das universidades, os deslocamentos tornam-se crescentemente difíceis.

Além disso, a disciplinarização, associada à concepção de conhecimento útil, também contribuiu de modo direto para a especialização crescente do conhecimento científico, não raro expressa metaforicamente pela palavra diversidade. A disciplina assume então papel fundamental tanto para a investigação quanto para o ensino, apresentando-se como categoria que simultaneamente organiza o conhecimento científico e estabelece os parâmetros para formação dos quadros científicos e profissionais, envolvidos evidentemente com a especialização do trabalho e divisão do conhecimento. Confirma-se por essa via a demonstração que faz Kuhn (1968) sobre a dependência estrutural da ciência em relação ao ensino: este forma tanto os usuários do conhecimento quanto aqueles que contribuirão diretamente para o avanço científico. A questão não se limita, portanto, à existência de tal relação, mas ao modo pelo qual ela se atualiza e se desenvolve. Tudo leva a crer que o ensino seja um componente interno do processo investigativo. Assim alterá-lo impõe uma alteração simultânea do ensino, o que se traduz em um projeto ambicioso porque se depara com a rotina das atividades acadêmicas subsumida pelas matrizes que a condicionam.

Não é de se estranhar, portanto, que, com a consolidação da articulação entre o ensino e a pesquisa, o maior triunfo do conhecimento científico moderno seja o de ser conhecido pelo que permite fazer, isto é, pelas suas conseqüências e seus benefícios. Tais benefícios se espalham pelo cotidiano e contribuem de modo efetivo para confirmar que a ciência tem o monopólio da verdade.

Semelhante modelo de inteligibilidade do real tem na racionalidade sua base e o seu produto, isto é, o conhecimento causal, fundado nas regularidades e previsibilidades dos fatos observados. O conhecimento científico, nesse sentido, qualifica-se pela presença de um modelo único, nascido nas ciências da natureza e importado para as demais. Observa-se que ele não se baseia na metáfora do método mas na imposição de uma representação mecânica prévia da realidade. A importação desse modelo 
para todas as áreas de conhecimento impõe-se como necessidade indiscutível do conhecimento científico universal (TÁLAMO \& CARVALHO, 2008).

\section{A pós-modernidade: ruptura com o único olhar}

A confiança no método da ciência moderna parece ter sido o fio condutor dos conflitos que redundaram no questionamento do próprio conhecimento científico. Segundo Hobsbawm (1966, p.350-352), os homens instruídos da segunda metade do século 19 encontravam-se realmente impressionados com as vitórias conquistadas, que a eles se apresentavam não apenas como impressionantes mas, sobretudo, finais. Todos os problemas efetivamente reconhecidos pareciam ter sido solucionados, restando apenas questões menores a serem investigadas: "Ninguém duvidava do progresso, tanto material como intelectual, já que parecia óbvio demais para ser negado" (HOBSBAWM, 1966, p.351). Entende-se então o motivo que leva a reconhecer nas ciências modernas um único paradigma, embora nele se inscrevessem diversidades e tensões que acabaram por comprometê-lo.

Os sinais de crise do modelo de inteligibilidade da ciência moderna manifestam-se no século 20 como resultado de uma série de condições teóricas e sociais. $\mathrm{O}$ modo dominante das ciências naturais baseado na mecânica newtoniana que tinha como premissa fundamental que a realidade física era determinada e apresentava simetria temporal, contemplando processos lineares cujas flutuações voltavam ao equilíbrio é contestada. Os cientistas naturais, especialmente a partir das últimas duas décadas do século 19, "encaram o futuro como sendo intrinsecamente indeterminado, vêem o equilíbrio como excepcional e entendem que os fenômenos materiais se afastam constantemente do equilíbrio" (SANTOS, 2004, p.127). O que está em jogo, então, são as idéias de determinismo e de mecanicismo que fundamentam a concepção de uma natureza passiva cuja descrição em termos de leis eternas competiria à ciência realizar. Em outras palavras, questionam-se os conceitos de lei e de causalidade que contribuem para a idéia de que os fenômenos fundam-se em um número restrito de condições que podem ser observadas e quantificadas. Simplifica-se, desse modo, a realidade que se vê desprovida de outros saberes, possivelmente mais compreensivos e interessantes para a natureza humana.

Para além de tais condições teóricas, é necessário também apontar aquelas de natureza social. A mais importante delas diz respeito, como observa Santos (1987), ao impacto da industrialização da ciência na sua dita autonomia e desinteresse. Tais valores que pareciam ser compartilhados espontaneamente pelos cientistas, viram-se, a partir das décadas de trinta e quarenta do século 20, afrontados pela industrialização da ciência que transferiu para o sistema econômico e político a definição das prioridades científicas. O mundo teve que encarar “ um modo de produção da ciência inclinado a transformar acidentes em ocorrências sistemáticas" (SANTOS, 1987, p.34). Essa mesma industrialização responde também pela estratificação do poder na comunidade científica, que confunde, não raro, titulações com competências intelectuais.

No entanto, a crise do paradigma da ciência moderna não leva a rejeitá-la como modo de conhecimento. Questiona antes seus fundamentos e a realoca como uma das possíveis explicações da realidade. Trata-se então de reconhecer os saberes e sua articulação em contextos como formas legítimas de conhecimento e não como imposição do caos ou de um "vale tudo" epistemológico (NUNES, 2004, p.62)

Boaventura Santos (1987) empreende um exercício especulativo, baseado em quatro teses, para discutir as possibilidades abertas pela crise da ciência moderna. São elas:

- $\quad \mathrm{I}^{\mathrm{a}}$ tese - Todo o conhecimento científico-natural é científico-social;

- $\quad 2^{\mathrm{a}}$ tese - Todo o conhecimento é local e total;

- $\quad 3^{a}$ tese - Todo o conhecimento é auto-conhecimento;

- $\quad 4^{\mathrm{a}}$ tese - Todo o conhecimento científico visa constituir-se em senso-comum;

Com a primeira tese descartam-se as dicotomias entre ciências naturais e ciências humanas, entre sujeito e objeto e entre permanência e mutabilidade. A universalidade do conhecimento expresso em uma única linguagem é também combatida ao mesmo tempo em que se reconhece a interferência do sujeito no próprio processo de investigação ( $3^{\mathrm{a}}$ tese). Por outro lado, com a proposição da noção de localismo ( $2^{\text {a }}$ tese), entende-se que o território exerce influência na produção do conhecimento, dificultando sua expressão única através de leis causais, o que acaba por associar o saber à sua necessária provisoriedade. Revalorizam-se, nesse sentido, os estudos humanísticos e os processos de analogia que lhe são peculiares, já que o texto da ciência tem de conviver com os demais textos da cultura, dialogando inclusive com o senso comum ( $4^{\mathrm{a}}$ tese).

A partir dessas quatro teses é possível desenvolver uma reflexão sobre a diversidade de saberes, uma " ordem emergente do conhecimento que é, ela própria, descrita como um paradigma alternativo..." (NUNES, 2004, p. 60). Semelhante ordem alternativa torna-se oficial com a adoção da preposição "após" na sua forma latinizada "pós" como prefixo da modernidade, cuja crise deflagra transformações nem sempre reconhecidas na sua profundidade e extensão.

A pós-modernidade não visa "uma ciência unificada nem sequer uma teoria geral, mas tão somente um conjunto de galerias temáticas onde convergem linhas de água, que até agora concebemos como objectos teóricos estanques" (SANTOS, 1987, p.10). A investigação interdisciplinar impacta positivamente os limites da racionalidade moderna, primeiro, porque associa-se às temáticas que representam problemas considerados relevantes, sob diferentes óticas e atores. Segundo, porque mobiliza diferentes conhecimentos e igualmente diferentes trajetos e meios para atacar o determinismo, propondo soluções 
que supõem necessariamente a atividade interpretativa e compreensiva do cientista.

\section{Interdisciplinaridade e os fluxos con- ceituais: o movimento estruturalista}

Entre as conseqüências visíveis do conhecimento gerado no âmbito da racionalidade moderna, destacamse sua especialização e a sua fragmentação. $\mathrm{O}$ número de disciplinas disponíveis, por exemplo, implica na impossibilidade de se conhecer em sua totalidade uma especialidade ou ainda de fazer conexões disciplinares necessárias entre elas. Não raro também o cientista se depara com zonas de indefinição em seu próprio campo, cuja interpretação demanda compartilhamento de conhecimentos ou de uma heurística.

De forma sintética, tem-se que, a par das relações entre as disciplinas que produzem e armazenam o conhecimento e o modo de configuração do ensino nelas assentado, existem outras formas de conhecimento - ditas alternativas -, reunidas no conceito de saberes, que o conhecimento científico apresenta uma trajetória que procura em outras formas de segmentação - quer do objeto, quer do método ou do seu próprio conteúdo - um modo de promoção compreensível da realidade. Nesse sentido, a interdisciplinaridade aparece como uma das formas possíveis de obtenção do saber compreensivo. Essa experiência se caracteriza pela aproximação de campos disciplinares diferentes para a solução de problemas específicos, especialmente através do compartilhamento de metodologias e a migração de conceitos (DOMINGUES, 2005).

Domingues (2005) considera que um dos exemplos emblemáticos de interdisciplinaridade no século 20 foi o estruturalismo. Através do compartilhamento de uma mesma metodologia - a análise estrutural - algumas disciplinas das ciências humanas aproximaram-se e obtiveram ganhos de cientificidade reconhecidos. Tanto isso é fato que o movimento impactou o ensino: uma universidade inteira, a de Vincennes, assumiu o projeto na sua integralidade. $\mathrm{O}$ fracasso do movimento, na década de 1980, não chega a descaracterizá-lo como experiência positiva de um "novo olhar sobre o mundo e a produção simbólica da sociedade”, identificando-se com "a história intelectual francesa a partir de 1945" ( DOSSE, 2007, p.11).

Ao redor da idéia de signo e de estrutura, Saussure e seus seguidores, desenvolveram uma abordagem que opera com a idéia de que no campo da cultura tudo que é adquirido, transmitido e compartilhado funda-se em um sistema passível de ser formalizado como signos. A idéia então é analisar a realidade cultural como língua, ou sistema de signos.

O signo, por sua vez, não se define de maneira isolada. A sua existência é relacional. A existência do signo deriva da estrutura do sistema, da qual ele é um nó ou um ponto da rede. O signo não tem existência prévia à estrutura que integra, resulta, de fato, dessa mesma estrutura. O seu valor é, portanto, negativo à medida que se configura sempre em relação aos demais signos que compartilham a mesma estrutura, implicando que a unidade e suas relações combinatórias sejam identificadas simultaneamente. Logo o interesse investigativo recai sobre as formas de expressão das relações - a estrutura- e não exatamente nos elementos que são imediatamente perceptíveis no universo da cultura.

Nos séculos 17 e 18, o termo estrutura tinha um caráter predominantemente descritivo, sinalizando para a " maneira como as partes integrantes de um ser concreto se organizam numa totalidade (DOSSE, p.24). A partir do século 19, o termo ganha o traço "abstrato" e responde por uma significação mais duradoura "que combina de maneira complexa as várias partes de um conjunto" (DOSSE, 2007, p.24). É justamente dessa noção que se origina o termo estrutura nas duas primeiras décadas século 20 e que confere o caráter metodológico revolucionário do movimento.

Embora o termo estruturalismo, tal como proposto por Saussure, derive do termo estrutura, esse contempla traços específicos que acabam por conferir-lhe uma aplicação ampla, que não oculta as fronteiras disciplinares da comunidade de pesquisadores que reúne. Assim, cunham-se expressões como o estruturalismo científico, estruturalismo semiológico e estruturalismo historicizado ou epistêmico.

De fato, ao redor do conceito de estrutura, unificase um pensamento constitutivo da cultura, expresso na definição feita por Focault (apud DOSSE, 2007, p.11) sobre o movimento estruturalista: "ele é a consciência despertada e inquieta do saber moderno". Nesse sentido, o estruturalismo permitiu a produção e afirmação de um pensamento que alterou profundamente as relações das humanidades com o mundo, especialmente, na sua fase áurea, da lingüística, da psicanálise e da antropologia.

Ressalta-se então que o estruturalismo não propõe uma importação de modelo entre as disciplinas. Tendo como recurso um método rigorosamente formalizado, passível de subsidiar e de sustentar um programa de análise em vários campos do saber, a interdisciplinaridade do movimento conta com premissas claras que constituem um legado de Saussure para as humanidades. São elas, de forma resumida:

1. A língua, ou seja, o sistema, pré-existe ao seu uso.

2. A língua é um fenômeno social cujas regras se desenvolvem a revelia do uso, significando que o conhecimento deve se projetar sobre a realidade que não é imediatamente visível (inconsciente estrutural, estrutura narrativa profunda, estrutura do mito etc.).

3. A língua é forma e não conteúdo, o que coloca em primeiro plano o estudo das formas e de suas relações, ao largo das substâncias (quadrado semiótico, oposições binárias etc.).

4. A noção de objeto como elaboração a partir de um ponto de vista, no caso a língua.

5. O discurso, ou seja, a mobilização do sistema da língua, tanto serve para traduzir quanto para mascarar a realidade, incluindo-se aí evidente- 
mente o discurso científico. Exemplo disso é a obra Mitologias de Barthes que "desmascara o espírito pequeno-burguês e chauvinista que inspira a estética do consumo moderno" (DOSSE, 2007, p.13). Nesse sentido, o estruturalismo "terá feito triunfar uma suspensão do sentido como meio de combater o eurocentrismo e as diversas formas de teologias ocidentalizadas em proveito de um certo pensamento diferencialista” (DOSSE, 2007, p.13).

No seu conjunto tais premissas permitem definir um método científico e uma terminologia compartilhados, sem vestígios de superioridade de um saber disciplinar sobre o outro. Isto é, as ciências humanas passam a dialogar a partir de método e de terminologia comuns. Além disso, no seu desenvolvimento, o movimento estruturalista realizará a sua construção e desconstrução, que nos anos 1980 do século 20 se auto-intitula pós-estruturalismo, marcado pela pesquisa do lugar do sujeito e do pensamento na sua relação com a ação. Nele, o conhecimento engaja-se na preocupação com o social. O pós-estruturalismo, nesse sentido, reinventa uma das preocupações do estruturalismo, qual seja o rompimento com as matrizes disciplinares erigidas artificialmente.

A análise estrutural estabelece um determinado padrão - a estrutura - para a construção de uma unidade, em qualquer nível. Nesse sentido, como se disse, a realização da interdisciplinaridade funda-se nas noções de signo e de estrutura decorrente da possibilidade de análise da cultura como linguagem. É essa metáfora subjacente ao pensamento estruturalista que torna possível a proposição das estruturas dos sistemas de significação. Tal estrutura sígnica resulta das relações e distribuição dos elementos de um sistema, donde a primazia do código sobre a mensagem e a afirmação de que o sistema lingüístico é forma e não conteúdo. Por exemplo, os termos "estrutura da comunicação", "estrutura social", "estrutura do mito" e "estrutura da língua", para citar apenas alguns, denotam a existência de uma realidade real e concreta, não observável, que modela a cultura, tornando possível o sentido. Sob esse aspecto, o pensamento estruturalista constrói um arcabouço interpretativo do sentido, fundado na metáfora da linguagem.

Em síntese, quaisquer que sejam as formas de aplicação do estruturalismo, cabe ao termo estrutura desempenhar o papel unificador. A ampliação do uso do vocábulo resulta não só da sua presença nos vários discursos da ciência mas também da sua integração à linguagem comum. Nos seus variados usos, percebe-se na palavra alguns traços constitutivos consagrados pelo movimento de origem, especialmente aqueles associados a uma forma que, embora não observável, incide sobre as ações concretas, conferindo-lhe sentido.

A partir do estruturalismo lingüístico, o termo estrutura caracteriza-se plenamente pelo seu uso interdisciplinar. Semelhante uso do conceito desenvolve-se através de dois movimentos complementares: a migração e a disseminação. Segundo Mari (2005), a migração consiste na transposição de conceitos metalingüísticos de um campo para outros, resultando em novas formas de significação e aplicação. Já a disseminação evidencia o efeito da migração sobre as produções locais, alterando o sentido pela contaminação com outros conceitos próprios do campo.

O conceito de estrutura na antropologia de LèviStrauss permite as formulações das lógicas internas subjacenteas ao real nas sociedades. Com isso ele se desvencilha de uma metodologia descritiva e empirista disseminada à época e promove uma interpretação que vai além da superfície dos sistemas sociais. Dito de outro modo, com a adoção do modelo estrutural lingüistico, agora interdisciplinar, Lévi-Strauss rompe com a filiação naturalista e biologista da antropologia francesa. As pesquisas que emprende a partir dessa ruptura são emblemáticas. Suas teses - As estruturas elementares do parentesco e a vida familiar e social dos índios Nhambiquara - constituem "um dos mais importantes acontecimentos da história intelectual do pós-guerra e a pedra angular nas fundações do projeto estruturalista" (DOSSE, 2007, p. 49).

O título da sua tese sobre as estruturas do parentesco passa rapidamente a ter valor conceitual, propondo-se como nuclear para a antropologia da época. Realiza-se, portanto, com a apropriação do termo da lingüística e sua consolidação em outro campo, a migração e a disseminação conceituais de maneira plena.

O impacto da revolução epistemológica levada a cabo por Lévi-Strauss não pode ser reduzido ao simples uso do termo ou do método. É preciso observar que tal apropriação fundamenta-se na existência de uma correspondência formal entre a estrutura da língua e o sistema de parentesco: o sistema de parentesco é uma linguagem, portanto. É essa hipótese harmonizadora que viabiliza as operações de migração e disseminação dos conceitos do estruturalismo lingüístico para a antropologia, o que responde ao princípio da economia, igualmente característico da interdisciplinaridade.

Confirma-se tal princípio, com a aplicação crescente do termo estrutura na sistematização de domínios aparentemente incoerentes. Assim, criam-se termos compostos com a palavra estrutura: estrutura do mito, estrutura da comunicação, estrutura do parentesco, ao lado daqueles que lhe são correlatos, como por exemplo, sistema e leis gerais.

Embora não se faça aqui uma análise ampla ou exaustiva da dimensão interdisciplinar do termo estrutura, os argumentos apresentados denotam que a interdependência entre migração e disseminação de termos atende ao princípio de economia dos sistemas simbólicos, potencializando a inserção e operacionalização de conceitos em campos metaforicamente aproximados. De fato, o uso interdisciplinar do termo promove uma circulação do conceito mais rápida e eficiente, conforme observa Mari (2005), dada a consistência do seu conteúdo informativo.

Enfim, resta observar que, com a interdisciplinaridade, a ciência pode exercer de maneira mais simples a 
complexa tarefa da circulação pública do conhecimento, adotando formas de comunicação que permitam o reconhecimento dos seus diferentes atores. Entende-se assim o motivo que levou um "treinador da seleção nacional [francesa] a anunciar na década de 1960, uma reorganização 'estruturalista' da sua equipe a fim de melhorar os resultados" (DOSSE, 2007, p.21). O treinador, de fato, traduz para o senso comum aquilo que é fundamental para o movimento estruturalista, ou seja, que a estrutura sustenta o processo e o que o jogo, nesse caso, nada mais é do que a sua atualização.

\section{Considerações finais: interdisciplinari- dade na constituição de novos campos}

A interdisciplinaridade, tal como foi abordada aqui, se apresenta como uma das possíveis estratégias de superação dos limites da racionalidade moderna. Ressaltase, no entanto, que ela é supostamente um mecanismo gestado na tensão entre os espaços formais e informais de produção do conhecimento, já que depende necessariamente dos processos comunicacionais para a realização das migrações e disseminações conceituais.

O recurso à interdisciplinaridade na pós-modernidade, por sua vez, apresenta-se como estratégia ou procedimento de apreensão do mundo de maneira mais precisa através do compartilhamento de experiências positivas. O princípio da economia, nesse sentido, torna menos arbitrárias as decisões conceituais, necessárias em todo campo do conhecimento para o enfrentamento e interpretação de seus problemas, procedimentos e objetos.

O uso do movimento estruturalista como exemplificação da interdisciplinaridade, não apenas demonstra a importância do procedimento na consolidação dos campos do conhecimento mas evidencia também que as operações interdisciplinares, quando satisfatoriamente desenvolvidas - o que pode ser atestado pelas heranças terminológicas - deixam marcas perenes na produção dos saberes.

Nesse sentido, pode-se afirmar que o movimento estruturalista não só consolidou no início do século 20 as ciências humanas mas deixou um legado importante para a reflexão sobre campos que ainda seriam elaborados.

A análise estrutural, por exemplo, encontra-se inscrita no contexto das ciências do impreciso, na denominação cunhada por Moles (1965). Esse autor considera que tal procedimento constitui abordagem privilegiada para a obtenção da precisão no trato de questões relativas a fenômenos vagos, seja por erro provável em sua determinação, seja pela indisponibilidade de técnicas de medidas adequadas para tratá-los, seja pelo fato de que se apresentam "vagos por essência". Nesse sentido, o recurso à análise ou método estrutural, qualquer que seja o campo de aplicação, se faz necessário para superar a imprecisão e a conceituação superficial e inadequada.

Sublinha-se, sob esse aspecto, que para Moles (1965, p.153) o recurso à análise estrutural permite “discernir dentro de todo 'espetáculo do mundo', dentro de todo fenômeno complexo deste, dentro de toda apa- rência observável" as unidades, regras de combinação que fundamentarão a reconstrução de um nível de precisão desejável definida pelas exigências da investigação. Essa combinatória apresenta-se como o código ou estrutura e deve ser compatível com a "representação da realidade tal como ela é percebida, em escala escolhida ou imposta ao observador pelas circunstâncias" (MOLES, 1965, p.153).

Outro exemplo da importância do conceito interdisciplinar de estrutura pode ser observado no texto de Saracevic (1999). Nele, o autor motivado pela curiosidade de conhecer com precisão o campo da ciência da informação e estabelecer uma estrutura que agregue não só os seus próprios trabalhos mas também os de seus colegas que declaram pertencer à ciência da informação inicia sua reflexão alegando que as definições lexicais de um campo do conhecimento nem sempre se mostram suficientemente exaustivas e precisas. Resolve então estabelecer uma premissa que atribui um caráter limitado ou quase nada discriminante ao assunto tratado ou abordado por um campo do conhecimento como elemento matricial para forjar sua identidade. Como já havia proposto em textos anteriores, elege os problemas tratados pela ciência da informação como diretrizes que definem os limites do campo.

Afirmar que o determinante não é o assunto mas os problemas, especialmente o modo de conhecê-los, exige o mapeamento das questões, das suas interpretações e dos possíveis leques de solução a elas propostos. Dando continuidade a essa reflexão, Saracevic (1999) adota a estratégia de identificar, por via retrospectiva, o que ele chama de idéias potentes do campo. São elas a recuperação da informação; a relevância e a interação, as quais formam um estrutura para o entendimento da própria ciência da informação.

O que está sendo afirmado, portanto, é que o desenvolvimento do campo do estudo dos problemas associados ao que o autor denomina de idéias potentes não caracteriza por si só a ciência da informação. É preciso modelizar estruturalmente tais elementos, através da sua identificação e combinatória.

Ao discorrer sobre a provável estrutura da ciência da informação, Saracevic (1999), referenciando vários autores da área, observa que o trabalho da disciplina incide em duas grandes subáreas - a de análise da informação e a de recuperação da informação - as quais contemplam especialidades adicionais. Lança mão, então, de um estudo empírico que gera, por meio do estudo de co-citações, a distribuição dos autores nessas duas subáreas. O padrão de distribuição obtido permite concluir que as subáreas não dialogam, não cooperam, enfim. A dificuldade de identificar parâmetros de distribuição e de combinação não permite nesse caso que se modelize a estrutura do campo da ciência da informação. Tem-se apenas as duas áreas isoladas e na ausência de conexão entre elas, uma indeterminação do campo.

Para reconhecer a fragilidade do campo, Saracevic (1999, p.1057) se vale de uma metáfora entre a ciência da informação e a Austrália: ambas apresentam uma gran- 
de área costeira desenvolvida com um interior bastante limitado. Ambas as áreas de um mesmo espaço geográfico e de um mesmo campo do conhecimento não estão equilibradamente desenvolvidas. Ambas igualmente não se conectam. Face a tal situação, há que se perguntar sobre os fundamentos teóricos do campo que reúne as duas áreas, se existem e se podem ser compartilhados. De algum modo, o esforço integrador dos trabalhos do campo deve ser incentivado e uma teoria unificada deve ser motivo de investigação para estruturá-lo efetivamente. Com isso, o exercício da interdisciplinaridade ganha em intensidade, já que não se vê restrito apenas à migração conceitual, mas realiza também sua disseminação.

Em síntese, o conceito de estrutura permite interrogar o campo da ciência da informação como lugar de produção de conhecimento e não apenas da proposição de soluções pontuais para melhoria de processos. A visão integradora defendida por Saracevic, a partir da mobilização do referido conceito, evidencia a importância da interdisciplinaridade mesmo quando ela não tem efetiva condição de desenvolvimento pleno. Indagar os motivos das limitações e as possibilidades de superá-las é, sem dúvida, uma forma de reativar metáforas e identificar significações e expressões esquecidas, cujas reapropriações permitam sistematizar, como o quer Saracevic, um trabalho teórico formal, amparado na evidência experimental que conecte as grandes áreas do campo que se encontram separados.

\section{Referências bibliográficas}

BURKE, P. Uma História Social do Conhecimento de Gutenberg a Diderot. Rio de Janeiro: Jorge Zahar, 2003.

CARAÇA, J. Um discurso sobre as ciências passadas e presentes. IN SANTOS, B. de S. (Org.) Conhecimento Prudente para uma vida decente. São Paulo: Cortez, 2004. p.183-190.

DOMINGUES, I. (Org.) Conhecimento e Transdisciplinaridade II. Belo Horizonte: Editora UFMG, 2005.

DOSSE, F. História do Estruturalismo. Bauru: Edusc, 2007.
HOBSBAWN, E. Era dos Extremos: o breve século XX:1914-1991. São Paulo: Companhia das Letras, 1995.

KUHN, T. A Estrutura das Revoluções Científicas. São Paulo: Perspectiva, 1968.

MARI, H. Metáfora, metonímia, denotação e conotação: a propósito da migração de conceitos. IN: DOMINGUES, I. (Org.) Conhecimento e Transdisciplinaridade II. Belo Horizonte: Editora UFMG, 2005. p.42-100.

MOLES, A.A. As ciências do impreciso. Rio de Janeiro: Civilização Brasileira, 1965.

NUNES, J.A. Um discurso sobre a ciência 16 anos depois. IN: SANTOS, B. de S. Org.) Conhecimento Prudente para uma vida decente. São Paulo: Cortez, 2004. p.59-84.

SANTOS, B. de S. Um discurso sobre as ciências. 8. Ed. Porto: Afrontamento, 1987.

SANTOS, B. de S. Para uma sociologia das ausências e uma sociologia das emergências. IN: SANTOS, B. de S. (Org.) Conhecimento Prudente para uma vida decente. São Paulo: Cortez, 2004. p.777-819.

TÁlAMO, M. F. G. M.; CARVALHO, R. Produção Científica e Informação. IN: GAIO, R. (org.) Metodologia de pesquisa e produção do conhecimento. Petrópolis: Vozes, 2008. p.105-116.

TÁlAMO, M. F. G. M.; SMIT, J. Ciência da Informação: a transgressão metodológica. IN: PINTO, V. B., CAVAlCANTE, L. E.; SILVA NETO, C. (org.) Ciência da Informação: Abordagens transdisciplinares gêneses e aplicações. Fortaleza: Edições UFC, 2007. p.23-47.

TEFKO, S. Information Science. Journal of the American Society for Informatios Science, 1999 50(12):10511063.

WALLERSTEIN, I. As estruturas do conhecimento ou quantas formas temos nós de conhecer? IN: SANTOS, B. de S. (Org.) Conhecimento Prudente para uma vida decente. São Paulo: Cortez, 2004. p.123-130.

\section{Sobre o autor}

\section{Maria de Fátima Gonçalves Moreira Tálamo}

Maria de Fátima Gonçalves Moreira Tálamo é bacharel em Lingüística pela Universidade Estadual de Campinas, mestre e doutora em Ciências da Comunicação pela Universidade de São Paulo. Docente aposentada da Escola de Comunicações e Artes da Universidade de São Paulo, onde atua como professora colaboradora e orientadora no programa de pós-graduação em Ciência da Informação - área de concentração Informação e Cultura. Desenvolve pesquisa na área de Organização da Informação e do Conhecimento. Coordena a seção "Documentação" do Projeto Eletromemória (USP, Unesp, Fapesp e Fundação Energia do Estado de São Paulo).È bolsista produtividade do CNPq. 